\title{
Clinical and Pathological Features of a typical Caprine Contagious Pustular Dermatitis
}

\author{
S. Vijayakumar ${ }^{1^{*}}$, P. Srinivasan ${ }^{2}$ and M. Ananthi ${ }^{1}$ \\ ${ }^{1}$ Department of Animal Husbandry, Erode, Tamil Nadu, India \\ ${ }^{2}$ Department of Veterinary pathology, Veterinary College and Research Institute, Namakkal, \\ Tamil Nadu, India \\ *Corresponding author
}

\begin{tabular}{|l|}
\hline Ke y w o r d s \\
$\begin{array}{l}\text { Contagious pustular } \\
\text { dermatitis, Goat, } \\
\text { Pathology, } \\
\text { Diagnosis and } \\
\text { control }\end{array}$ \\
\hline Article Info \\
\hline $\begin{array}{l}\text { Accepted: } \\
\text { 04 May } 2019 \\
\text { Available Online: } \\
\text { 10 June 2019 }\end{array}$ \\
\hline
\end{tabular}

\section{A B S T R A C T}

Contagious pustular dermatitis (CPD) is an acute, highly contagious, zoonotic, debilitating and economically important viral non-systematic eruptive skin disease of small ruminants. In this report, occurrence of atypical caprine contagious pustular dermatitis associated with pneumonia in a goat flock is described. An outbreak of pox like disease was noticed in four out of 18 non-descript goats during June 2018, in Erode district of Tamil Nadu. Affected animals showed multiple, discrete, edematous nodular lesions and crust formation throughout its body surface with respiratory symptoms. Among the four animals one was collapsed. On postmortem examination, the anterioventral lobes of lungs showed patches of consolidation and multifocal grayish white areas in the remaining lung lobes. Histopathological examination of the skin revealed orthokeratotic and parakeratotic hyperkeratosis, epidermal hyperplasia, degenerative changes in the stratum spinosum, and large eosinophilic intracytoplasmic inclusion bodies in few keratinocytes. Lung showed diffuse to focal suppurative bronchopneumonia and the mediastinal lymph nodes exhibited depletion of the lymphocytes in the paracortical regions. Skin scab and lung samples were found positive for contagious pustular dermatitis virus by the polymerase chain reaction. Treatment of CPD complicated with bronchopneumonia is ineffective, hence the farmer was advised to cull the affected goats, disinfect the animal house premises with $3 \%$ iodine solution. Due to the effective culling and adaptation of strict biosecurity measures, following the initial outbreak, no other animals in the goat flock were affected.

\section{Introduction}

Contagious pustular dermatitis (CPD) is an emerging, infectious and zoonotic viral disease of sheep and goat caused by epitheliotrophic virus called CPD virus belonging to genus parapoxvirus of the family Poxviridae (Tedla et al., 2018). The disease commonly called as contagious ecthyma, orf, contagious pustular stomatitis, infectious labial dermatitis, sore mouth, and scabby mouth and usually more severe in goats than in sheep (De Wet and Murie, 2011; Pal et al., 2013). In India, outbreaks occur 
more frequently during periods of extreme temperature such as late summer and winter (Venkatesan et al., 2012). Persistently infected carrier goats are the main source of disease and infection can relapse during time of stress (Nettleton et al., 1996). Traditionally, the disease is described as being confined to the muzzle and lips of three to six months age old kids, although adults may also at times be affected. In more severe cases proliferative nodular lesions disseminated to skin of the eyes, feet, vulva, udder and scrotum (De La Concha-Bermejillo et al., 2003). The morbidity of the disease may reach up to $100 \%$ and mortality due to secondary bacterial infections may reach to 15\% (Gumbrell and McGregor, 1997). Most of the times treatment of disseminated CPD complicated with bronchopneumonia are ineffective (Nandi et al., 2011). The disease is usually diagnosed based on the characteristic lesions on the anatomic areas of predilection. The diagnostic challenge for the practitioner becomes greater when the disease is more severe and virus strays from its usual distribution which requires laboratory confirmation by serological and nucleic acidbased techniques (Venkatesan et al., 2012). This paper describes an atypical case of contagious pustular dermatitis associated with pneumonia in a goat flock.

\section{Materials and Methods}

An outbreak of pox like disease was reported in a goat flock during June 2018, in Erode district of Tamil Nadu. The farmer maintained 18 non-descript goats in loose housing system and an open pasture system of grazing. All animals were examined and manifestations of clinical signs and lesions were recorded. Among the 18 animals four showed anorexia, dullness, cough, dyspnea and presence of crusty muco purulent yellow nasal discharge with a rise in body temperature (41.0 ${ }^{\circ} \mathrm{C} \cdot 41.8^{\circ} \mathrm{C}$ ) whereas the remaining fourteen animals were apparently normal with fair body condition. On clinical examination, affected animals showed multiple discrete edematous nodular lesions with crust formation throughout its body surface and on lung auscultation mild crackling sounds were observed. Among the four affected animals one was collapsed in spite of rigorous treatment and submitted for postmortem examination. On the basis of the skin and lung lesions a tentative diagnosis of Goat pox was made. The skin crust, lung and mediastinal lymph node samples were collected for histopathology and polymerase Chain reaction (samples with $50 \%$ glycerol saline) sent to Central University laboratory TANUVAS for confirmative diagnosis.

\section{Results and Discussion}

Contagious pustular dermatitis is likely to be an increasingly important health issue in the small holder and emerging goat production systems in Tamil Nadu because vaccination is currently unavailable and the disease may compromise the marketable weight of the live animal. The disease usually affects young animals and is not difficult to diagnose clinically or pathologically when the lesions are present in the typical locations such as lips, muzzle and teats. However the clinical diagnosis may become complex when the disease is more severe and lesions are present in the atypical locations as in the present case since the disease likely to be confused with goat pox. Scab and lung samples were found positive for contagious pustular dermatitis virus by the polymerase chain reaction (Hosamani et al., 2007; Ramesh et al., 2008). The disease causes morbidity up to $100 \%$ and the mortality between 5\%-15\% (Housawi et al., 1991; Constable et al., 2017), however in the present incidence it was 22 and 05 per cent respectively which was lower than the previous reports. Low morbidity and mortality might be due to early detection and 
culling of the affected animals with adaptation of proper biosecurity measures. The present outbreak was recorded in 5 to 7 month age old goats during the month of June i.e late summer (Bouzanch et al., 2013; Maan et al., 2014).

On physical examination affected animals showed respiratory distress and elevation of body temperature. Multiple discrete, edematous, tumefactive nodular lesions (vary from 4 to $9 \mathrm{~mm}$ in diameter) with smooth margins were noticed throughout the body surface (Fig. 1). Lesions were not pruritic or only mildly so. In one animal skin nodular lesions was grey in colour with crust formation (Fig. 2). In one animal, subcutaneous oedema of the head and neck was severe giving a bottle-jaw appearance (Nandi et al., 2011). On postmortem examination, the lungs showed patches of firm and red discoloration of the anterioventral lobes (Fig. 3). Multifocal grayish white areas of 2 to $6 \mathrm{~mm}$ diameter were noticed in the remaining lung lobes. On section, the grayish white areas of lung revealed oozing of purulent exudates. This was in agreement with (Constable et al., 2017), who also described systemic invasion in which the infection may extend into the trachea leading to bronchopneumonia in severe cases of CPD.

Histopathological examination of the skin lesions showed prominent areas of orthokeratotic and parakeratotic hyperkeratosis. Epidermal hyperplasia with prominent rete ridges extending into the dermis was observed. Degenerative changes were noticed within the stratum spinosum, with numerous swollen, vacuolated cells having pyknotic nuclei. A few keratinocytes contained large, eosinophilic intracytoplasmic inclusion bodies. Pustule formation was noticed at the margins of the lesions. The underlying dermis showed extensive sub acute inflammation, with moderate to marked aggregations of a mixture of inflammatory cells and tissue necrosis (Fig. 4). These observations were in accordance with earlier reports of contagious pustular dermatitis (Nandi et al., 2011; Gelberg, 2012). Bronchial, bronchiolar and alveolar lumen were filled with inflammatory exudates consist of polymorphonuclear cells mixed with bacterial colonies and cellular debris, where as the interstitium showed hyperemia and mild edema. Diffuse to focal distributions of pneumonic lesions were noticed in various lobes of lungs (Gelberg, 2012).

Fig.1\&2 Multiple discrete, edematous, tumefactive nodular lesions with smooth margins throughout the body surface \& Greyish skin nodular lesions with crust formation
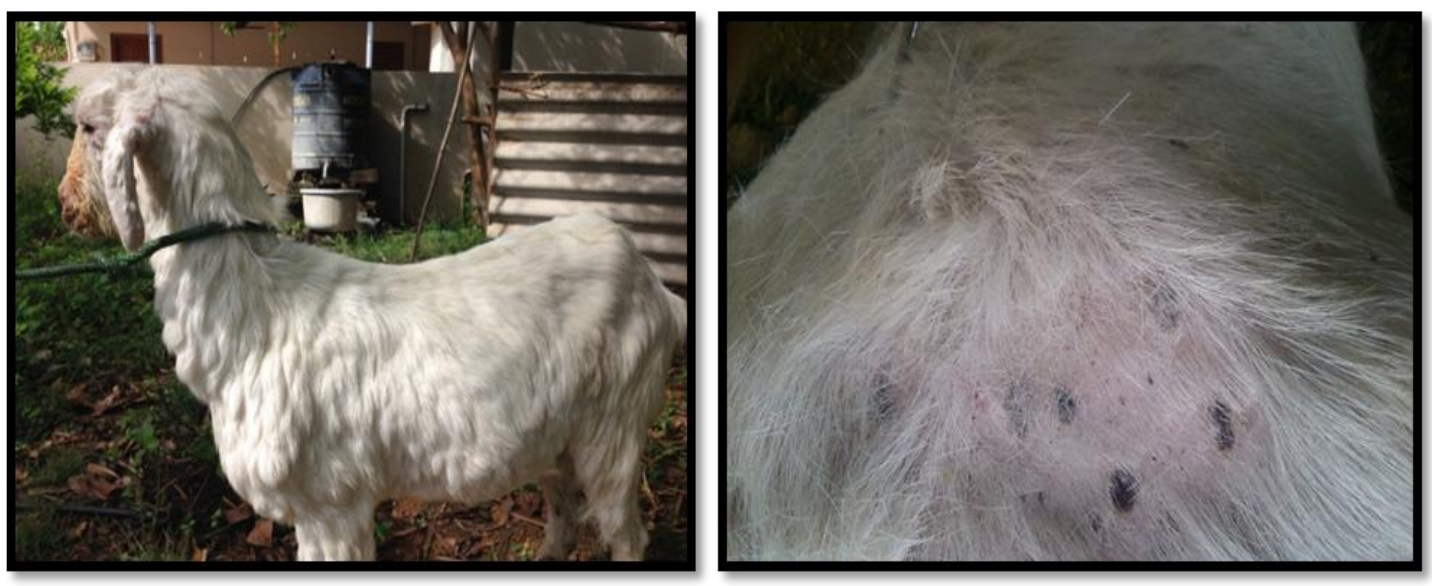
Fig.3\&4 Consolidation of the anterioventral lobe and multifocal greyish white areas in the remaining lobes of lungs \& Bronchiolar and alveolar lumen are filled with inflammatory exudates consist of polymorphonuclear cells mixed with bacterial colonies and cellular debris. $\mathrm{H}$ $\& \mathrm{E} \times 100$

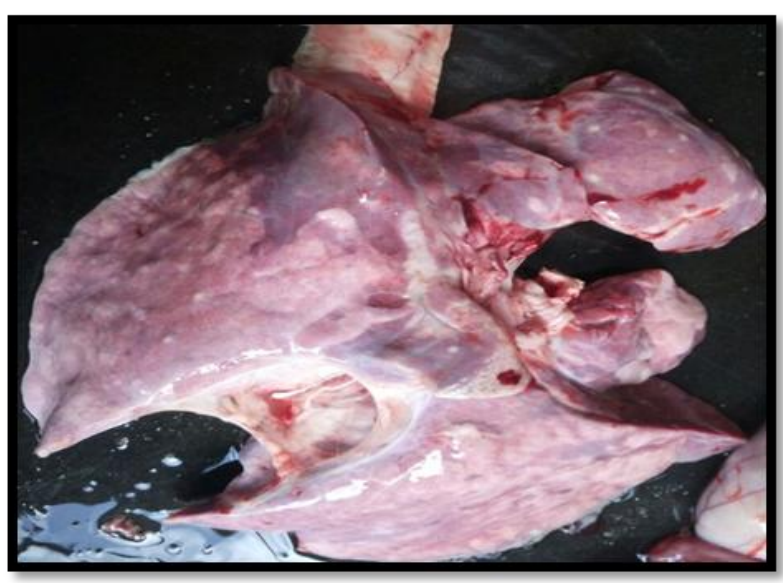

Depletion of the lymphocytic population in the paracortical regions and absence of germinal centers in the mediastinal lymph nodes were noticed which indicates pulmonary defense mechanism was compromised and facilitated bacterial colonization and development of bronchopneumonia in the present study.

Majority of times treatment of CPD complicated with bronchopneumonia is ineffective (Nettleton et al., 1996). Hence the farmer was advised to cull the affected goats, disinfect the premises of animal house with $3 \%$ iodine solution and incinerate all infected materials extracted from sick animals for effective control of disease and reduce the risk of new infection in the flock. Due to the effective culling and adaptation of strict biosecurity measures, following the initial outbreak, no other animals in the goat flock were affected.

In conclusion, outbreaks of contagious pustular dermatitis in goats with an aberrant distribution of lesions present a novel diagnostic challenge to the small ruminant practitioner. The results obtained in this

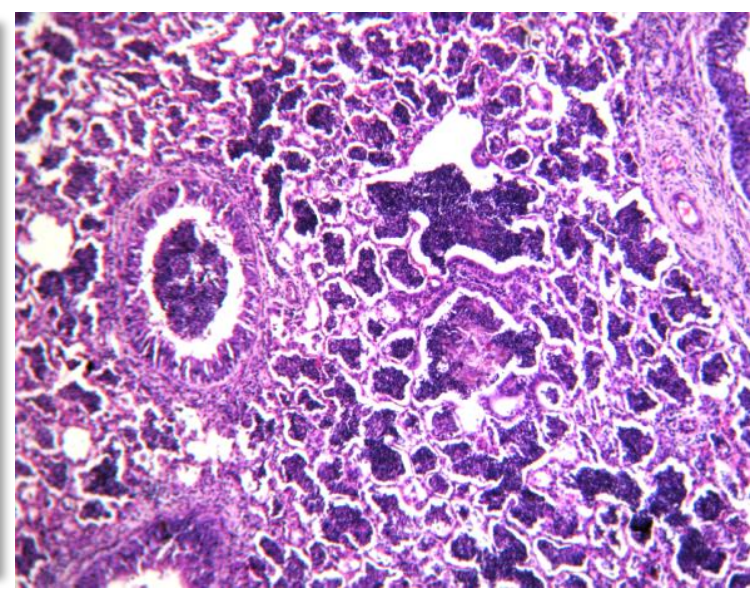

investigation clearly demonstrate the value of submitting of diagnostic material to the laboratory, facilitated the accurate diagnosis of disease of uncertain etiology. Early detection of CPD is essential for effective control of the disease and it also helpful in minimizing economic losses to the farmers and also prevents significant zoonotic implications to the farmers as well as animal health professionals.

\section{References}

Bouznach, A., S. Hahn, Y. Stram, S. Menasherov, N. Edery, N. Shicaht, G. Kenigswald and Perl S. 2013. Case Report: Contagious Ecthyma Deviations in the Anatomicalv Appearance of Lesions in an Outbreak in Lambs in Israel. Israel Journal of Veterinary Medicine. 68 (4): 246 - 251.

Constable, P.D., K.W. Hinchcliff, S.H, Done and Grunberg W. 2017. A textbook of the diseases of cattle, horses, sheep, pigs and goats, $11^{\text {th }}$ edn, Saunders Elsevier, Edinburgh London.

De La Concha-Bermejillo, A., J. Guo Z. Zhang and Waldron D. 2003. Severe 
persistent orf in young goats. J. vet. Diagn. Invest. 15: 423-431.

De Wet, C., and Murie, J. 2011. Two cases of ecthyma contagiosum (orf). Scott. Med. J., 56:59.

Gelberg, H.B., 2012. Alimentary system and the peritoneum, omentum, mesentery, and peritoneal cavity. In: JF Zachary, MD McGavin (Eds), Pathologic Basis of Veterinary Disease, 5th edition, Elsevier, St. Louis., pp. 326-327.

Gumbrell, R.C., and McGregor D.A. 1997. Outbreak of severe fatal orf in lambs. Veterinary Record. 141: 150-151.

Hosamani, M., S. Yadav, D. J. Kallesh, B. Mondal, V. Bhanuprakash and Singh R. K. 2007. Isolation and characterization of an Indian orf virus from goats. Zoonoses Public Hlth, 54(5): 204-208.

Housawi, FM., E.M.E. AbuElzein, M.M. AminAl and Afaleq A I. 1991. Contagious pustular dermatitis (orf) infection in sheep and goats in Saudi Arabia. Veterinary Record 128: 550551

Maan, S., A. Kumar, K. Batra, M. Singh, T. Nanda, A. Ghosh and Maan N.S. 2014. Isolation and molecular characterization of contagious pustular dermatitis virus from Rajasthan, India. Virus Dis. 25(3): 376-380.

Nandi, S., K.De. Ujjwal and S. Chowdhury (2011) Current status of contagious ecthyma or orf disease in goat and sheep- A global perspective Small
Ruminant Research 96:73-82.

Nettleton, P.F., J. Brebner, I. Pow, J.A. Gilray, G.D. Bell and Reid H.D. 1996. Tissue culture- propagated orf virus vaccine protects lambs from orf virus challenge. Veterinary Record. 138:184186.

Nourani, H., and Maleki, 2006. Contagious ecthyma: case report and review, Pakistan Journal of Biological Sciences. 9 (13): 2543-2545.

Pal, M., S. Tesfaye and Dave P 2013. Zoonoses Occupationally Acquired By Abattoir Workers. J. Environ. Occu. Sci. 2(3):155-162.

Ramesh, A., V.S. Vadivoo, S. Suresh Babu and Saravanabava K 2008 Confirmatory diagnosis of contagious ecthyma by amplification of the GIF / Il-2 gene by PCR. Tamilnadu J. Veterinary \& Animal Sciences. 4(6):208-210.

Tedla, M., N. Berhan, W. Molla, W. Temesgen and Alemu S 2018. Molecular identification and investigations of contagious ecthyma (Orf virus) in small ruminants, North west Ethiopia. BMC Vet. Res. (1):13.

Venkatesan, G., V. Bhanuprakash, V. Balamurugan, D.P. Bora, M. Prabhu, R. Yogisharadhya and Pandey A.B. 2012. Rapid detection and quantification of Orf virus from infected scab materials of sheep and goats. Acta virologica. 56: 81-83.

\section{How to cite this article:}

Vijayakumar, S., P. Srinivasan and Ananthi, M. 2019. Clinical and Pathological Features of a typical Caprine Contagious Pustular Dermatitis. Int.J.Curr.Microbiol.App.Sci. 8(06): 269-273. doi: https://doi.org/10.20546/ijcmas.2019.806.030 